\title{
Sodium bicarbonate versus hyaloronidase in peribulbar anaesthesia
}

\author{
Nelly Nazareth ${ }^{1}$, Sarita Gonsalves ${ }^{2, *}$, Vivekand. ${ }^{3}$, F. E. A Rodrigues ${ }^{4}$ \\ ${ }^{\mathbf{1}}$ Associate Professor, ${ }^{2}$ Assistant Professor, ${ }^{3,4}$ Professor, Dept. of Ophthalmology, ${ }^{1,2,4}$ Father Muller Medical College, Mangalore, \\ Karnataka, ${ }^{3}$ Alluri Sitarama Raju Academy of Medical Sciences, Eluru, Andhra Pradesh, India \\ *Corresponding Author: Sarita Gonsalves \\ Email: gonsalvessarita@gmail.com
}

\begin{abstract}
The goals of safe, effective anaesthesia is to achieve good surface anaesthesia, akinesia, hypotony, analgesia. Peribulbar anesthesia is a safer to minimize complications of retrobulbar anesthesia. Hyaluronidase is used to aid in the better diffusion of anaesthetic solution. The cost, limited shelf life, risk of anaphlylaxsis are its limiting factors. Hence the need for studying the efficacy of sodium bicarbonate as an alternative to hyaluronidase.

Materials and Methods: Prospective randomized study on 100 patients who underwent cataract surgery. Group A was injected with an anaesthetic mixture containing $0.5 \%$ bupivacaine, lignocaine with adrenaline with $1 \mathrm{ml}$ hyaluronidase. Group B was injected with an anaesthetic mixture of $0.5 \%$ bupivacaine and lignocaine $2 \%$ to which $7.5 \%$ sodium bicarbonate was added.

Results: Group A onset of anaesthesia 5 minutes 46(92\%), 50(100\%) of group B five minutes. Akinetic action of agent 1 better than agent 2., chemosis $16(32 \%)$ in group A,18 (34\%) group B. Lid edema nil group A, 17 (34\%) of group B. Subconjunctival hemorrhage 3(6\%) group A, 4(8\%) group B. Peribulbar hemorrhage nil group A, 2(4\%) group B. Globe perforation none. Raised IOP 1(2\%) group A, 12(24\%) group B Overall effective anaesthesia, akinesia achieved in 49 patients (98\%) of group A, 43 $(86 \%)$ of group B. Systemic complication in $1(2 \%)$ of group B.

Conclusion: The present study showed that sodium bicarbonate is a effective alternative to hyaluronidase in peribulbar anaesthesia.
\end{abstract}

Keywords: Cataract surgery, Hyaluronidase, Peribulbar anaesthesia, Sodium bicarbonate.

\section{Introduction}

Peribulbar anaesthesia is a safe technique when compared to retrobulbar anaesthesia for cataract surgery. However the requirement of a large volume and inconsistent onset are the chief drawbacks. The anaesthetic solution used contains $2 \%$ lignocaine, $0.5 \%$ bupivacaine along with hyaluronidase which helps in better diffusion of the anaesthetic agent. However its cost, risk of anaphylaxis and shorter shelf life are the chief drawbacks. Sodium bicarbonate on the other hand is cheaper, easily available and has a lower risk of anaphylaxis. Hence the need to study sodium bicarbonate as an effective alternative to hyaluronidase.

\section{Materials and Methods}

A prospective randomized study on 100 patients who underwent cataract surgery under local anesthesia from January 2009 to December 20011 were included in this study.

The exclusion criteria were: (1) Patients on preoperative sedatives, analgesics and anxiolytics (2) Patients with profound cognitive impairment (3) Apprehensive patients who required sedatives or anxiolytics (4) Patients with documented allergy to hyaluronidase and lidocaine.

Documentation of variables included: age, gender, visual acuity as Snellen's fraction, any coexisting vision threatening ocular pathology or drug allergy. General medical problems such as diabetes mellitus (DM), hypertension (HT), and ischemic heart disease (IHD) were also recorded.
After a written informed consent 50 patients were assigned randomly to either group A or group B respectively. Patients who underwent cataract surgery with local anesthesia using 2\% lignocaine and $0.5 \%$ bupivacaine buffered with hyaluronidase and sodium bicarbonate were included in group $\mathrm{A}$ and $\mathrm{B}$ respectively.

Anaesthetic Solution: Group A was injected with an anaesthetic mixture containing $0.5 \%$ bupivacaine $(2 \mathrm{ml})$ and lignocaine $2 \%(3 \mathrm{ml})$ with adrenaline $(1: 200000)$ with $1 \mathrm{ml}$ hyaluronidase (Agent 1) (1500 IU-in $30 \mathrm{ml}$ of lignocaine, $50 \mathrm{IU} / \mathrm{nil}$, ). Group B was injected with an anaesthetic mixture of $0.5 \%$ bupivacaine $(2 \mathrm{ml})$ and lignocaine $2 \%$ [(3 ml) with $1 ; 200000$ adrenaline $)]$ to which $7.5 \%$ sodium bicarbonate (Agent 2 ) was added (1 ml-30 cc lignocaine).

The peribulbar block was administered to 100 cases by a single person who wasunaware of the constituents of the mixture used in the two groups. Single point anesthesia was administered at the infero temporal quadrant; total of $6 \mathrm{cc}$ was injected at the junction of medial $2 / 3$ and lateral $1 / 3$ of the lower lid with the eye in the primary position of gaze. Anesthesia and akinesia was graded as per Table 1 . 
Table 1: Grading of anaesthesia and akinesias ${ }^{3}$

\begin{tabular}{|l|c|c|}
\hline \multicolumn{1}{|c|}{ Movements } & Degree of function & $\begin{array}{c}\text { Degree of } \\
\text { function score }\end{array}$ \\
\hline Levator function & Full function/no block & 3 \\
\hline & Moderate function/mild block & 2 \\
\hline & Mild function/moderate block & 1 \\
\hline & Nil function/complete block & 0 \\
\hline Orbicularis function & Full function/No block & 2 \\
\hline & Reduced function/partial block & 1 \\
\hline & Nil function/complete block & 0 \\
\hline Ocular motility & Full function & 2 \\
\hline & Reduced function & 1 \\
\hline & Nil & 0 \\
\hline
\end{tabular}

Based on the scoring system akinesia was given scores from $0-7$ at $5,10,15$ and 20 minutes respectively. Patients with score $>3$, a supplementary injection of the same mixture was given at the end of ten minutes. Time taken for the onset of akinesia and anesthesia was recorded. Duration of the anesthetic effect and the effectiveness was recorded. Immediate complications like subconjunctival hemorrhage, chemosis, lid edema, effectiveness of block and systemic side effects were recorded. Systemic parameters pulse, blood pressure, respiratory rate were observed. The above observations were repeated at the end of 2 hours, 4 hours, 1 day, 7 days and 6 weeks post operatively to check for any local and systemic complications related to the anesthesia.

\section{Statistical Analysis}

Statistical analyses were performed using the statistical software (SPSS for Windows, ver.18.0 SPSS Science, Chicago, IL). The results were expressed as mean \pm SD if the variables were continuous, and as percentage, if categorical. Results were analyzed using paired t test, chi square tests, Fischers exact test and Mann Whitney test. P- value of $\leq 0.05$ was considered significant.

\section{Observations and Results}

Of the 100 patients in this study 27 (54\%) in group A were females and $23(46 \%)$ were males and in group B, $27(54 \%)$ were females and 23(46\%) were males.

In group A there were no patients aged below 40 years, 2 (4\%), 12 (24\%),17 (34\%) and 19 (38\%) patients were present in age group of 40-49, 50-59,6069,70-79 years respectively. In group B had 1(2\%) patient in age group below 40 years, 3(6\%), 12(24\%), $17(34 \%), 13(26 \%)$ and $4(8 \%)$ patients were present in agegroup of 40-49,50-59,60-69,70-79 and $\geq 80$ years respectively. The mean age of patients in group $\mathrm{A}$ and group B 64.74 and 63.34 years respectively.

Onset of Anaesthesia: Only 46(92\%) patients attained anesthesia within 5 minutes in group A whereas all the $50(100 \%)$ patients in group B attained anaesthesia in five minutes. The remaining $4(8 \%)$ of patients of group A attained anaesthesia after ten minutes of administering local anaesthesia.

$P$ value 0.059 which was statistically not significant.

Onset of Akinetic Action: In group A, 17 (34\%), 22 $(66.7 \%), 8(72.7 \%)$ and $3(100 \%)$ patients had a score of 0 representing total akinesia at end of 5, 10, 15 and 20 minutes respectively. In group B, 4(8\%), 22(47.8\%), $14(58.3 \%)$ and $4(80 \%)$ patients had a score of 0 representing total akinesia at end of 5, 10, 15 and 20 minutes respectively. (Table 2 )

Table 2: Onset of akinetic action

\begin{tabular}{|c|c|c|c|c|c|c|c|c|c|c|c|c|c|c|c|c|c|c|}
\hline \multirow{3}{*}{$\begin{array}{l}\text { Time } \\
\text { (Min) }\end{array}$} & \multirow[t]{3}{*}{ Agent } & \multicolumn{15}{|c|}{ Scoring } & \multirow{2}{*}{\multicolumn{2}{|c|}{ Total N }} \\
\hline & & 0 & \multicolumn{3}{|c|}{1} & 2 & \multicolumn{2}{|c|}{3} & \multicolumn{2}{|c|}{4} & \multicolumn{3}{|c|}{5} & \multicolumn{2}{|c|}{6} & \multirow{2}{*}{$\begin{array}{c}7 \\
N \\
\end{array}$} & & \\
\hline & & $\mathrm{N}$ & $\%$ & $\mathrm{~N}$ & $\%$ & $\mathrm{~N}$ & $\%$ & $\mathrm{~N}$ & $\%$ & $\mathrm{~N}$ & $\%$ & $\mathrm{~N}$ & $\%$ & $\mathrm{~N}$ & $\%$ & & $\%$ & \\
\hline \multirow[t]{2}{*}{5} & Agent 1 & 17 & 34 & 21 & 42 & 7 & 14 & 3 & 6 & 0 & 0 & 0 & 0 & 0 & 0 & 2 & 1 & 50 \\
\hline & Agent 2 & 4 & 8 & 20 & 40 & 13 & 26 & 7 & 14 & 3 & 6 & 2 & 4 & 1 & 2 & 0 & 0 & 50 \\
\hline \multirow[t]{2}{*}{10} & Agent 1 & 22 & 66.7 & 7 & 21.2 & 3 & 9.1 & 0 & 0 & 1 & 3 & 0 & 0 & 0 & 0 & 0 & 0 & 33 \\
\hline & Agent 2 & 22 & 47.8 & 13 & 28.3 & 8 & 17.4 & 1 & 2.2 & 2 & 4 & 0 & 0 & 0 & 0 & 0 & 0 & 46 \\
\hline \multirow[t]{2}{*}{15} & Agent 1 & 8 & 72.7 & 3 & 7.3 & 0 & 0 & 0 & 0 & 0 & 0 & 0 & 0 & 0 & 0 & 0 & 0 & 11 \\
\hline & Agent 2 & 14 & 58.3 & 8 & 33.3 & 0 & 0 & 2 & 8.3 & 0 & 0 & 0 & 0 & 0 & 0 & 0 & 0 & 24 \\
\hline \multirow[t]{2}{*}{20} & Agent 1 & 3 & 100 & 0 & 0 & 0 & 0 & 0 & 0 & 0 & 0 & 0 & 0 & 0 & 0 & 0 & 0 & 3 \\
\hline & Agent 2 & 4 & 80 & 1 & 20 & 0 & 0 & 0 & 0 & 0 & 0 & 0 & 0 & 0 & 0 & 0 & 0 & 5 \\
\hline
\end{tabular}

Agent 1- Sodium hyaluronidase, Agent 2- 7.5\% Sodium bicarbonate, N-Number of patients, \% - percentage 
P- value: $P$ value at 5,10 and 15 minutes were $<0.001$, 0.006 and 0.035 respectively which were significant proving that the akinetic action of agent 1 was better than agent 2. $P$ value for akinesia at the end of 20 minutes was 0.317 revealing no statistically significant association. (Table 3).

Table 3. $P$ values at different intervals

\begin{tabular}{|c|c|c|c|c|c|c|c|c|}
\hline Time (Minutes) & Agent & $\mathbf{N}$ & Min & Max & Mean & Sd & $Z$ value & p value \\
\hline \multirow[t]{2}{*}{5} & Agent 1 & 50 & 0 & 7 & 1.16 & 1.476 & \multirow[t]{2}{*}{3.514} & \multirow[t]{2}{*}{$<0.001$} \\
\hline & Agent 2 & 50 & 0 & 6 & 1.9 & 1.344 & & \\
\hline \multirow[t]{2}{*}{10} & Agent 1 & 50 & 0 & 4 & 0.34 & 0.772 & \multirow[t]{2}{*}{2.749} & \multirow[t]{2}{*}{0.006} \\
\hline & Agent 2 & 50 & 0 & 4 & 0.8 & 1.05 & & \\
\hline \multirow[t]{2}{*}{15} & Agent 1 & 50 & 0 & 1 & 0.06 & 0.24 & \multirow[t]{2}{*}{2.104} & \multirow[t]{2}{*}{0.035} \\
\hline & Agent 2 & 50 & 0 & 3 & 0.28 & 0.671 & & \\
\hline \multirow[t]{2}{*}{20} & Agent 1 & 50 & 0 & 0 & 0 & 0 & \multirow[t]{2}{*}{1} & \multirow[t]{2}{*}{0.317} \\
\hline & Agent 2 & 50 & 0 & 1 & 0.02 & .141. & & \\
\hline
\end{tabular}

Agent 1- Sodium hyaluronidase, Agent 2- 7.5\% Sodium bicarbonate, N-Number of patients, Min- Minimum score, Max- Maximum score, Mean- mean score, Sd- Standard deviation, Z Value- From Fischers exact test.

Supplementary Anesthesia: The first supplementary anaesthesia was given to 12 patients from group A and 14 patients from group B. Second supplementary anaesthesia was given to 2 patients of each group. $\mathrm{P}$ value $=0.648$ show no significant association in need for supplementary anesthesia between the groups (Table 4).

Table 4: Number of patients requiring supplementary anaesthesia

\begin{tabular}{|l|c|c|}
\hline & & N \\
\hline First supplementary & Group A & 12 \\
\cline { 2 - 3 } anaesthesia & Group B & 14 \\
\hline $\begin{array}{l}\text { Second supplementary } \\
\text { anesthesia }\end{array}$ & Group A & 2 \\
\cline { 2 - 3 } & Group B & 2 \\
\hline
\end{tabular}

N-Number of patients

Pre-intra Operative Ocular Complications: There were no major adverse effects noted after the administration of anaesthesia. The most common side effect seen was chemosis which was present in 16 (32\%) patients in group A and $18(34 \%)$ in group B. None of the patients of group A had lid edema whereas 17 (34\%) of group B developed lid edema following injection. Sub conjunctival hemorrhage occurred in $3(6 \%)$ of group A and $4(8 \%)$ of group B. Peribulbar hemorrhage was not seen in any patient of group $\mathrm{A}$ while it was noted in 2(4\%) of group B. Globe perforation was not seen in any of the groups. Vitreous bulge and forward thrust, with increased IOP was seen in $1(2 \%)$ of group A and $12(24 \%)$ of group B. (Table 5)
Table 5: Pre-intra operative ocular complications

\begin{tabular}{|l|c|c|c|}
\hline \multirow{2}{*}{ Chemosis } & & $\mathbf{N}$ & $\mathbf{\%}$ \\
\hline \multirow{2}{*}{$\begin{array}{l}\text { Subconjunctival } \\
\text { hemorrhage }\end{array}$} & Group A & 16 & 32 \\
\cline { 2 - 4 } & Group B & 18 & 34 \\
\hline Peribulbar hemorrhage & Group A & 3 & 6 \\
\cline { 2 - 4 } & Group B & 4 & 8 \\
\cline { 2 - 4 } & Group A & 0 & \\
\hline \multirow{2}{*}{ Perforation } & Group B & 2 & 4 \\
\hline & Group A & 0 & \\
\hline \multirow{2}{*}{ Lid edema } & Group B & 0 & \\
\hline \multirow{2}{*}{ Vitreous bulge } & Group A & 0 & \\
\cline { 2 - 4 } & Group B & 17 & 34 \\
\hline & Group A & 1 & 2 \\
\hline & Group B & 12 & 24 \\
\hline
\end{tabular}

N-Number of patients, $\%$ - percentage

Post-operative Assessment: In the post-operative period these patients were assessed based on the postoperative extra ocular movements (EOM), ptosis and pain at 2 hours, 4 hours, 1 day, 7 days and 6 weeks. Of the 50 patients in group A the EOM recovered in $23(46 \%)$ patients in 2 hours, 34(68\%) in 4 hours and all 50 by day 1 . While in group B 17(34\%) patients recovered in 2 hours, 29(58\%) in 4 hours and all 50 by 1 day. In group A ptosis was present in $47(94 \%)$, $28(56 \%), 8(16 \%)$ of patients at the end of 2,4 hours and by day 1 respectively. In group B ptosis was present in 48(96\%), $43(86 \%)$ and $21(42 \%)$ of patients at the end of 2, 4 hours and by day 1 respectively. By day 7 ptosis had recovered in all patients of group A, but persisted in 4(8\%) patients of group B. At 6 weeks ptosis in all patients of group B had recovered. Of group A $4(8 \%)$ complained of pain in the operated eye at 2 hours, $3(6 \%)$ at 4 hours and $1(2 \%)$ on day 1 . While in group B $10(20 \%)$ patients experienced pain at 2 hours, $9(18 \%)$ at 4 hours and $3(6 \%)$ on day 1 . At the end of 1 week all patients recovered from pain. (Table 6) 
Table 6: Post-operative assessment

\begin{tabular}{|c|c|c|c|c|c|c|}
\hline & & & $\mathbf{N}$ & $\%$ & $\mathbf{N}$ & $\%$ \\
\hline \multirow[t]{2}{*}{ EOM } & \multirow[t]{2}{*}{$2 \mathrm{hrs}$} & Agent 1 & 27 & 54 & 23 & 46 \\
\hline & & Agent 2 & 33 & 66 & 17 & 34 \\
\hline \multirow[t]{2}{*}{ PTOSIS } & \multirow[t]{2}{*}{$2 \mathrm{hrs}$} & Agent 1 & 3 & 6 & 47 & 94 \\
\hline & & Agent 2 & 2 & 4 & 48 & 96 \\
\hline \multirow[t]{2}{*}{ PAIN } & \multirow[t]{2}{*}{$2 \mathrm{hrs}$} & Agent 1 & 46 & 92 & 4 & 8 \\
\hline & & Agent 2 & 40 & 80 & 10 & 20 \\
\hline \multirow[t]{2}{*}{ EOM } & \multirow[t]{2}{*}{$4 \mathrm{hrs}$} & Agent 1 & 16 & 32 & 34 & 68 \\
\hline & & Agent 2 & 21 & 42 & 29 & 58 \\
\hline \multirow[t]{2}{*}{ PTOSIS } & \multirow[t]{2}{*}{$4 \mathrm{hrs}$} & Agent 1 & 22 & 44 & 28 & 56 \\
\hline & & Agent 2 & 7 & 14 & 43 & 86 \\
\hline \multirow[t]{2}{*}{ PAIN } & \multirow[t]{2}{*}{$4 \mathrm{hrs}$} & Agent 1 & 47 & 94 & 3 & 6 \\
\hline & & Agent 2 & 41 & 82 & 9 & 18 \\
\hline \multirow[t]{2}{*}{ EOM } & \multirow[t]{2}{*}{ Day 1} & Agent 1 & 0 & 0 & 50 & 100 \\
\hline & & Agent 2 & 0 & 0 & 50 & 100 \\
\hline \multirow[t]{2}{*}{ PTOSIS } & \multirow[t]{2}{*}{ Day 1} & Agent 1 & 42 & 84 & 8 & 16 \\
\hline & & Agent 2 & 29 & 58 & 21 & 42 \\
\hline \multirow{2}{*}{ PAIN } & \multirow{2}{*}{ Day 1} & Agent 1 & 49 & 98 & 1 & 2 \\
\hline & & Agent 2 & 47 & 94 & 3 & 6 \\
\hline \multirow[t]{2}{*}{ EOM } & \multirow[t]{2}{*}{ Day 7} & Agent 1 & 0 & 0 & 50 & 100 \\
\hline & & Agent 2 & 0 & 0 & 50 & 100 \\
\hline \multirow[t]{2}{*}{ PTOSIS } & \multirow[t]{2}{*}{ Day 7} & Agent 1 & 50 & 100 & 0 & 0 \\
\hline & & Agent 2 & 46 & 92 & 4 & 8 \\
\hline \multirow[t]{2}{*}{ PAIN } & \multirow[t]{2}{*}{ Day 7} & Agent 1 & 50 & 100 & 0 & 0 \\
\hline & & Agent 2 & 50 & 100 & 0 & 0 \\
\hline \multirow[t]{2}{*}{ EOM } & \multirow[t]{2}{*}{6 weeks } & Agent 1 & 0 & 0 & 50 & 100 \\
\hline & & Agent 2 & 0 & 0 & 50 & 100 \\
\hline \multirow[t]{2}{*}{ PTOSIS } & \multirow[t]{2}{*}{6 weeks } & Agent 1 & 50 & 100 & 0 & 0 \\
\hline & & Agent 2 & 50 & 100 & 0 & 0 \\
\hline \multirow[t]{2}{*}{ PAIN } & \multirow[t]{2}{*}{6 weeks } & Agent 1 & 50 & 100 & 0 & 0 \\
\hline & & Agent 2 & 50 & 100 & 0 & 0 \\
\hline
\end{tabular}

Agent 1- Sodium hyaluronidase, Agent 2- 7.5\% Sodium bicarbonate, N-Number of patients, $\%$ - percentage

\section{Discussion}

Most surgeons local peribulbar anesthesia is a pre requisite for cataract surgery. The peribulbar technique has gained much popularity as compared to its predecessor the retrobulbar technique as it has an added advantage of causing hypotony of the globe due to the loss in tone of the extra ocular muscles.Several adjuvants are used to aid in effective anesthesia and analgesia. Hyaluronidase is a commonly used enzyme, it was first introduced by Atkinson in 1949, it aids in the diffusion of the anesthetic agent. ${ }^{4}$

In this study we have compared the onset of action, effectiveness and complications of peribulbar anesthesia in two groups, one which achieved anesthesia with hyaluronidase and the other group with sodium bicarbonate.

Several studies have noted improved onset time with alkalinisation of local anesthetic solutions. Galido et al reported reduction in the time of onset with alkalinisation. ${ }^{5}$ Zahl et al 30 also demonstrated faster onset with sodium bicarbonate in ocular anaesthesia. ${ }^{6}$ Sodium bicarbonate when added to local anesthetics causes them to be more basic by rising their $\mathrm{pH}$. This causes the drug to exist in the non ionized form which crosses the perinueral sheath more easily thereby reducing the time of onset. It is also the active form of the drug, non-cation form which increases the bio availability and thereby the onset of action. However, in our study group A showed the onset of anesthesia to be 5 minutes in $46(92 \%)$ of patients and all $50(100 \%)$ of group B attained anesthesia in five minutes. $4(8 \%)$ of patients of group B attained anesthesia in ten minutes of. The $p$ value 0.059 , was statistically not significant. Hence both agents used have the same action regarding onset of anesthesia according to our study.

On onset of akinesia in our study showed a $p$ value at 5,10 and 15 minutes were $<0.001,0.006$ and 0.035 respectively which were significant proving that the akinetic action of agent 1 was better than agent 2 . At the end of 20 minutes the $p$ value was 0.317 which was not significant. This proves that agent 1 has an earlier onset of akinesia and a better grading score than agent 2. On the contrary the studies conducted by Srinivasan et al conclude that there was no significant difference between the two groups regarding akinesia. ${ }^{7}$ 
The first supplementary anesthesia was given to 12 patients from group A and 14 patients from group B. Second supplementary anesthesia was given to 2 patients of each group. Applying the chi square test the $\mathrm{p}$ value was 0.648 which was insignificant. There is no significant difference in the supplementary block rate.

Agarwal V., Athamkar N. S. et al in 1994 had demonstrated the efficacy of single point infero temporal anaesthesia. ${ }^{8}$ Similar results were also reported by Paul, Arnold in 1992 with single point peribulbar anaesthesia. ${ }^{9}$ While Morsen C.D., Holden R. Found a high success rate of anesthesia with hyaluronidase and reduced the need for supplementation. ${ }^{10}$

Effective in terms of duration of anaesthesia and akinesia was achieved in 49 patients $(98 \%)$ of group A and $43(86 \%)$ of patients of group B. Here p value is 0.027 which is significant. Earlier studies have not reported the duration of anaesthesia except Srinivasan et al who showed similar duration for both the groups.

The ocular complications considered were chemosis, lid edema, sub conjunctival hemorrhage, peribulbar hemorrhage, vitreous bulge, globe perforation. Of these chemosis was the most common complication which was seen equally in each group. It did not persist after adequate massage and did not hamper surgery. Lid edema was seen in no patients of group A but in 17(34\%) of group B.P value was $<0.001$ hence was highly significant proving group $B$ had lesser diffusion property when compared to group A. Sub conjunctival hemorrhage had equal incidence in both groups hence was not significant. Peribulbar hemorrhage occurred in 2 patients of group B but none in group A. This number was statistically insignificant. Globe perforation being a rare complication was not seen in both the groups. David BD et al in their study had complications such as orbital hemorrhage in $0.74 \%$ cases, globe perforation in $0.006 \%$, expulsive choroidal hemorrhage in $0.013 \%$ and grand mal seizures in $0.006 \%$. There were no systemic complications recorded in both groups. David B. and Richard M. "evaluated the efficacy and complication rates of 16 , 224 consecutive peribulbar blocks which were single point. The incidence of complications was low. ${ }^{11,12}$ Vitreous bulge and forward thrust, with increased IOP was seen in 1(2\%) of group A and 12(24\%) of group B. This complication was seen due to the volume of the drug used and inadequate digital massage. However, this was not severe enough to warrant the postponement of surgery. With smaller volume of the anesthetic adequate digital massage we thought the occurrence of this complication could be avoided. Rao V. et al evaluated peribulbar anesthesia, consisting of a single injection of $5 \mathrm{cc}$ anesthetic solution with a 26 gauge needle. They observed complete anesthesia in 15 minutes withno significantcomplications. Therefore, deemed it as safe, simple, economical means of anaesthesia. ${ }^{13}$

\section{Conclusion}

The present study showed that sodium bicarbonate is an effective alternative to hyaluronidase in peribulbar anaesthesia with a faster onset of anesthetic action and the duration of anaesthesia. However the onset of akinesia was prolonged and the rate of ocular complications were higher. Sodium bicarbonate can become an effective alternate agent to hyaluronidase provided some precautions are exercised.

\section{References}

1. Morsan C.D., Holden R., The effects of adrenaline, hyaluronidase in peribulbar anaesthesia, Eye. 1992;6:290292.

2. Galido A., ph adjusted local anaesthetic, clinical experience in regional anaesthesia. 1983;8:35-40.

3. Aslam S. Effect of Hyaluronidase on ocular motility and eyelid function in subtenons anaesthesia: Randomised Control Trial, Eye. 2006;3:174-177.

4. Atkinson W.S. Observation on anaesthesia for ocular surgery, Transactions of American academy of ophthalmology 1956;60:376.

5. Galido A., ph adjusted local anaesthetic, clinical experience in regional anaesthesia.1983;8:35-40.

6. Zahl K., Jordan A., McGroarty J. Peribulbar anaestl1esiaEffect of sodium bicarbonate on a mixture of lidocaine, bupivacaine and hyaluronidase with or without epinephrine. Ophthalmology. 1991;98:239-42.

7. Srinivasan M., Vamshidhar M., Gopal R., Banushree, Sodium bicarbonate - An alternative to hyaluronidase in ocular anaesthesia for cataract surgery. Indian Journal of Ophthalmology. 2000;48:285-9.

8. Agarwal V., Athamkar N.S. Single injection low volume periocular anaesthesia in 1000 cases. Journal of Cataract and Refractive Surgery. 1994;20:61.

9. Arnold P.N. Prospective study of single injection of peribulbar technique. Journal of Cataract and Refractive Surgery. 1992;18:157-161.

10. Morsan C.D., Holden R. The effects of adrenaline, hyaluronidase in peribulbar anaesthesia. Eye. 1992;6:290292.

11. David B.D., Richard M., Efficacy and complication rate of 16,224 peribulbar blocks. Journal of Cataract and Refractive Surgery. 1994;20:327-337.

12. David B.D., Mandel M., Peribulbar anaesthesia, A review of technique and complications, Ophthalmology clinics of North America. 1990;3:101-110.

13. Rao V.A., Sukumaran D., Kumar A., A modified technique of peribulbar anaesthesia. Journal of Tamil Nadu Ophthalmic Association. 1996;2:13-15.

How to cite this article: Nazareth N., Gonsalves S., Vivekand U, Rodrigues F. E. A. Sodium bicarbonate versus hyaloronidase in peribulbar anaesthesia. Indian J Clin Exp Ophthalmol. 2018;4(4):487-491. 